\title{
FUGITIVOS DEL HOGAR
}

\section{Julio Almeida*}

Al hecho claro de que la socialización del niño español se hace hoy más fuera que dentro del hogar, se añade la circunstancia de que no se sale del mismo al final de la adolescencia, como se hacía desde tiempo inmemorial hasta ayer, como se sigue haciendo en muchos países occidentales; quizá (caso estupendo) ni a los veinticinco o treinta, y entonces se cuadra la paradoja: por un lado, el hogar familiar se habita tan poco que las habitaciones pasan a denominarse, han pasado a ser, meros dormitorios; hasta la biblioteca puede llamarse dormitorio; por otro, tan singular socialización, que estorba la autonomía de la personalidad en desarrollo, no les impide a los chicos quedarse en la casa paterna hasta mucho después de la adolescencia. Hijos y padres educados todos en el barullo cotidiano — sobrinos, suegros, etcétera - configuran así un peculiar e inextricable universo que se combina con la vida conversada del bar y con la movida correspondiente. La vividez incomparable de los bares españoles, más numerosos que los de muchos otros países juntos, depende menos de su posible comodidad que de una vida familiar que expulsa tanto como atrae; el bar se nutre en buena medida de la imposible habitabilidad de tales viviendas-dormitorios, de los constantes ruidos de vecinos incapaces de ensimismamiento. Dicen que ahora el paro dificulta y agrava la emancipación de los hijos, pero todo parece indicar que el familismo viene de muy atrás. ${ }^{1}$ Y no se sabe si la disminución del paro, que amontona a la gente en pisos ridículos donde mayormente se conversa a voz en grito y se oye la radio y se ve la televisión en pantalla grande, resolverá el problema que nos ocupa.

* Catedrático de Sociología de EU, Universidad de Córdoba, y miembro de la Asociación Castellano-Manchega de Sociología. 


\section{RADICADOS EN EL HOGAR}

Los datos muestran y demuestran que en las casas españolas viven más personas que en las otras viviendas europeas. «Las estadísticas de alargamiento de la cohabitación entre padres e hijos durante la década de los ochenta, con períodos de dependencia doméstica muy superiores a los europeos... son también un indicador importante del papel de amortiguador social que ha jugado la familia en relación con el choque del paro... $\rangle^{2}$ En otro lugar, en una extensa obra sobre Historia de las mujeres, se recuerda que la cohabitación entre generaciones y fratrías adultas había dejado de ser la regla al final de la Edad Media. Poco después de la segunda Guerra Mundial el baby-boom coincidió con una escasez de viviendas, pero treinta años más tarde disminuye el número de personas en cada casa. «Los hogares en los que no había más de una o dos personas constituían más de la mitad del total de hogares en los países escandinavos, Austria,

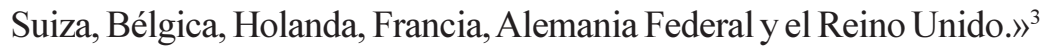

En los países mencionados ha aumentado considerablemente el número de personas que viven solas. A juicio de la socióloga citada, «este aumento de la cantidad de personas que viven solas se debe en gran parte a la ruptura generalizada de la cohabitación entre las generaciones adultas, al crecimiento general de la esperanza de vida y a la mayor longevidad de las mujeres». Pese a las alarmas, la familia se mantiene con buena salud. Ahora bien, ya no se trata de aquella gran familia tradicional que educaba a sus muchos hijos en parte en la calle, sin coches hasta hace pocos decenios; en plan piara, como decía un chico educado entre diez hermanos. En la mayoría de los países europeos y en Estados Unidos, los hijos piensan irse del hogar paterno al terminar la escuela secundaria, que coincide con el final de la adolescencia; aunque sigan estudiando, ya se consideran adultos que pueden y deben contribuir a subvenir a sus necesidades. ${ }^{4}$

La peculiaridad española no estriba sólo en el hecho de que ahora parece difícil encontrar empleo: es que muchos jóvenes consideran natural seguir viviendo donde los nacieron, parasitando sine die a sus mayores. No se les ocurre que podrían abandonar el nido familiar y embridar su existencia. Se diría que van a quedarse en la adolescencia para siempre. Tan lejos de la mentalidad europea como de la española preindustrial, nuestros jóvenes actuales (tan numerosos, por otra parte) ignoran la ley natural que obliga a separarse de la teta nutricia y a vivir autónomos; se hallan tan bien instalados bajo el techo en que nacieron, que parecen dispuestos a no dejarlo jamás.

En El niño difícil (1930) calculaba Alfred Adler que del 50 al 60 por ciento de todos los niños han sido acostumbrados a depender de otras personas. «Esta falta de independencia se manifiesta a lo largo de su vida: todo es difícil para ellos; no confían en su propia capacidad.» Setenta años después tendríamos que hacer otros cálculos. Sin duda los jóvenes españoles actuales dependen demasiado de sus progenitores y temen echarse a volar por su cuenta. 


\section{FUGITIVOS DEL HOGAR}

Pero hay más, el otro lado de la cuestión. No se trata sólo del hecho calculable de que en las casas españolas viven o intentan convivir más personas que en las de otros países; casi nadie ignora que suele tratarse de pisos tan pequeños que difícilmente se puede vivir en ellos. Por lo general son viviendas sin habitaciones habitables, y su conversión en dormitorios no es ningún desliz semántico; a decir verdad, esos habitáculos se habitan poco porque no dan para mucho. A veces los periódicos dan la imposible noticia de que en tal sitio de veinte metros cuadrados viven veinte personas; pero querrán decir que pernoctan. Por lo tanto, cuando se habla de la formidable socia(bi)lidad de los españoles, hay que matizar. Los frecuentadísimos bares, en efecto, no se nutren sólo de su posible comodidad o atractivo, como sucede en otros países; se llenan también, así como calles y paseos, porque el minúsculo hogar carece de sitio y de posibilidad de sosiego y expulsa a sus inquilinos, que vienen y van constantemente. Al exponer estas ideas en clase, una alumna comentó con inteligencia: En realidad, estamos en casa de visita.

Ahora se habla mucho de fracaso escolar, pero yo me pregunto cómo puede estudiar un chico en viviendas que tienen tan pocos metros cuadrados por persona. ¿Cómo trabajar con tanta gente y tantos decibelios: en el piso propio, en el de arriba o abajo, en el de al lado? Ya los constructores se cuidan de que la estructura del edificio sea endeble, de que techos y tabiques aíslen poco o nada; el amor al ruido y los horarios extravagantes los ponemos nosotros, o nos los impone algún vecino.

Vemos que las apariencias engañan; como dice Berger, las cosas no son lo que parecen. La calle viva, los innúmeros bares y cafés casi siempre abiertos y llenos de gente, creo que dependen precisamente de la fuga de quienes no disponen en su casa de espacio y calma suficientes; por lo demás, evidentemente, nuestra extroversión y nuestra verborrea arrancan de una socialización brutal que nos habitúa desde niños a convivir y a conversar sin medida. ¿Leer El Quijote? Es un libro demasiado largo, contestan sin rebozo algunos pobrecitos estudiantes.

Hablamos de la vida cotidiana, pero todo está conexionado. Cuando, en 1924, reflexionaba Ortega en el centenario del nacimiento de Kant, ya advirtió nuestro filósofo que el meridional vive «condenado al barullo de la gran plazuela cósmica y no se hallará jamás verdaderamente solo». No es retórica. La situación del español es inversa de la del alemán, para quien el yo está siempre consigo; su ser es un serpara-sí, el Fürsichsein hegeliano. «Durante quince años de cátedra he podido adquirir la más amplia experiencia de la enorme dificultad con que una cabeza española llega a comprender este concepto [de autoconciencia, o conciencia de sí, Selbstbewusstsein]. En cambio, me sorprendió muchas veces en los seminarios filosóficos alemanes la facilidad con que el principiante penetra dentro de él. Era el pato recién nacido que se lanza recto a la laguna, su elemento.» ${ }^{5}$ Poco después, en ¿Qué es Filosofía?, precisará que la idea de subjetividad, principio básico de la 
Edad Moderna, es tan fácil y obvia para los hombres del norte como incomprensible para nosotros; y esta incomprensión «es una de las razones por las cuales los pueblos mediterráneos no han sido nunca plenamente modernos». Verdaderamente, la exaltación del yo tiene largas consecuencias. ¿Puede alguien pensar todavía que la historia es un proceso natural?

\section{LA VIDA APARENTE}

Con la Reforma, los europeos protestantes arribaron a la convicción de que cada hombre responde de su vida ante el sumo Hacedor sin subterfugios colectivistas y debe por tanto dedicarse a un trabajo determinado, aunque sea humilde. En cambio el español, que hacía la guerra divinal por casi todo el mundo, confiaba más en Dios y se cuidaba menos de los negocios cismundanos; menos de las cosas que de la honra de las personas, más del ser que de los resultados; quality frente a performance, en el esquema de variables de Parsons. Cuando se convive con españoles o con norteamericanos o europeos del norte, se ve que los primeros, más atentos a la presión ajena, parecen figurantes de una vida social (máximamente en Sevilla) y afectan un nivel de vida visible superior al de aquéllos, mayor en todo caso que el nivel efectivo. Esto lo ha observado Juan José Linz, pero lo hemos visto cuantos hemos vivido fuera. A su modo lo había señalado Gracián, al promediar el siglo XVII, en El Criticón: como primera en todo lo malo, la soberbia cogió la delantera y se acomodó en España. "Allí vive y reina con todos sus aliados, la Estimación propia, el Desprecio ajeno, el querer mandarlo todo y servir a nadie, hacer del don Diego y vengo de los godos, el Lucir, el Campear, el Alabarse, el Hablar mucho, alto y hueco, la Gravedad, el Fausto, el Brío, con todo género de Presunción, y todo esto desde el noble hasta el más plebeyo.»

Los extranjeros que nos visitan no pueden entender las arcanas razones que llevan a nuestras mujeres a acicalarse tanto un día cualquiera para salir de casa a comprar tomates. Como ellos y ellas van a lo suyo, en el sentido meliorativo (el ocuparse de sus propios asuntos, que los ingleses parece que aprendieron en el Quijote, Dios mío, ¿será verdad?), ignoran que nosotros vamos al teatro de la calle para vernos y hablar de lo divino y de lo humano; ignoran sobre todo nuestro pavor al qué dirán, un qué dirán que en el rigor de los términos es una presionante opinión que decimos todos sin inhibiciones. El espectáculo de una calle o un paseo de Córdoba, por ejemplo, tiene poco que ver con la mundana religiosidad de esos protestantes lanzados con fiera circunspección a su clase de piano, a su hora de inglés, a su deporte favorito. Ellos no han venido al mundo a charlar sin tasa. Esas diferencias, por consiguiente, tienen menos que ver con el clima que con la historia, y si una muchacha andaluza quiere aprender a tocar el piano será censurada como ninguna sueca puede imaginar, y la marearán constantemente con una pregunta desoladora: ¿Y eso, para qué? 
En fin, ensimismarse es un verbo espléndido que sólo tenemos en español, pero ¿quién sabe por qué? Aquí es más difícil ensimismarse que en Francia o en Dinamarca. En 1926 Unamuno escribía a su amigo Jean Cassou: «¿Por qué no lanza usted en francés un s'ensoimêmer?» Probablemente no necesitan conjugarlo.

\section{A MODO DE CONCLUSIÓN. UNA HABITACIÓN PROPIA}

La historia no concluye nunca, pero he de cerrar esta breve nota sobre la paradójica vida fugitiva de tantos españoles. Peor que la situación del varón fue durante milenios la de la mujer, menos libre y autónoma. Pues bien, al final de los años veinte, cuando las mujeres occidentales empezaban a estudiar y a votar y a entrar en la escena pública, un grupo de feministas preguntaron a Virginia Woolf por las mujeres y la novela. ¿Por qué había tan pocas mujeres escritoras? Y la novelista contestó con sensatez que para poder escribir novelas, el quid latente de la pregunta, una mujer debe tener dinero y una habitación propia.

Una habitación propia —room inglesa grande, no dormitorio minúsculo, quizá para varios - es la condición material necesaria; las otras condiciones (talento y dedicación) difícilmente pueden desarrollarse sin aquélla. Lo que en 1929 pedía una mujer de la elite de Bloomsbury, podemos generalizarlo hoy y suponer que sin un espacio y un tiempo propios, hay poco que hacer y se busca la salvación en la huida. ¿A qué obedecen si no esas extrañísimas movidas que fascinan a nuestros jóvenes? No se refugiarían en ellas si tuvieran verdaderos hogares, es decir, espaciosos y amables.

Cuando murió Luis Rosales, Julián Marías se preguntaba por qué entre todo lo que escribió el poeta prefería La casa encendida y agregaba: «La vida humana transcurre en una casa; en muchas, que en definitiva son la misma.» Yo creo que estas palabras del maestro podrían discutirse en el sentido que vengo señalando aquí. En círculos altos o cultivados, sí; en otros países, sin duda; pero para una infinidad de españoles, la vida transcurre más fuera que dentro de casa, y esto desde párvulos, cuyo horario — a diferencia de lo que se hace por ahí- se iguala bárbaramente con el de los mayores: con el de los niños de doce años, con el de su maestra. Para muchos, vivir en su hogar es muy difícil, porque faltan metros o sobra gente, o las dos cosas. Muchos hispanos podrían suscribir las palabras del protagonista de Don Segundo Sombra: «La calle fue mi paraíso, la casa mi tortura.»

El inglés afirma, por lo visto, que su casa es su castillo, My home is my castle. Yo he pensado en ocasiones que no pocos españoles, fugados desde luego de su hogar, dirán más bien: Mi casa es mi dormitorio. 


\section{NOTAS}

${ }^{1}$ Véase mi término "Familismo", en: UÑA, O. y HERNÁNDEZ, A. (2003): Diccionario de sociología, ESIC, Madrid.

${ }^{2}$ ZALDIVAR, C.A. y CASTELLS, M., (1992): España fin de siglo, Madrid, pp, 126-327.

"LEFAUCHEUR,N.; "Maternidad, familia, Estado", en DUBY,G. Y PERROT, M. ( 1993): Historia de las mujeres en Occidente, 5 vols., Madrid, p.444

${ }^{4}$ Para Estados Unidos, puede verse VARENNE, H., "Love and liberty. La familia americana contemporánea", en la obra colectiva dirigida por BURGUIÈRE y otros (1988): Historia de la familia, 2 vols., II,Madrid, pp. 425-448

"Reflexiones de centenario. 1724-1924". OC, IV, p.35 ss. 